\title{
Regional differences in awareness of tobacco advertising and promotion in China: findings from the ITC China Survey
}

\author{
Yan Yang, ${ }^{1}$ Lin Li, ${ }^{2}$ Hua-Hie Yong, ${ }^{2}$ Ron Borland ${ }^{2} \mathrm{Xi} \mathrm{Wu}^{1}{ }^{1}$ Oiang Li, ${ }^{1,3}$ \\ Changbao $\mathrm{Wu}^{4}{ }^{4}$ Kin Foong ${ }^{5}$
}

${ }^{1}$ Center for Chronic and Non-communicable Disease Control and Prevention, Chinese Center for Disease Control and Prevention, Beijing, China ${ }^{2}$ VicHealth Centre for Tobacco Control, The Cancer Council Victoria, Melbourne, Australia ${ }^{3}$ Department of Psychology, University of Waterloo, Waterloo, Canada

${ }^{4}$ Department of Statistics and Actuarial Science, University of Waterloo, Waterloo, Canada ${ }^{5}$ National Poison Centre, Universiti Sains Malaysia, Penang, Malaysia

\section{Correspondence to}

Professor Yan Yang, National Center for Chronic and Non-communicable Disease Control and Prevention, Chinese Center for Disease Control and Prevention, 27 Nanwei Road, Beijing, 100050, P R China; Email:

yangyan8288@hotmail.com

Received 1 February 2009 Accepted 12 November 2009

\section{ABSTRACT}

Objective To examine whether levels of, and factors related to, awareness of tobacco advertising and promotion differ across six cities in China.

Methods Data from wave 1 of the International Tobacco Control (ITC) China Survey (April to August 2006) were analysed. The ITC China Survey employed a multistage sampling design in Beijing, Shenyang, Shanghai, Changsha, Guangzhou and Yinchuan. Face-to-face interviews were conducted with a total of 4763 smokers and 1259 non-smokers. Multivariate logistic regression models were used to identify factors associated with awareness of tobacco advertising and promotion.

Results The overall levels of noticing advertisements varied considerably by city. Cities reporting lower levels of advertising tended to report higher levels of point of sale activity. Noticing tobacco industry promotions was associated with more positive attitudes to tobacco companies.

Conclusion The awareness of tobacco advertising and promotional activities was not homogeneous across the six Chinese cities, suggesting variations in the tobacco industry's activities and the diversity of implementing a central set of laws to restrict tobacco promotion. This study clearly demonstrates the need to work with the implementation agencies if national laws are to be properly enforced.

\section{INTRODUCTION}

Tobacco advertising and promotion increases tobacco consumption among smokers and encourages smoking uptake among non-users, especially young people. ${ }^{1-7}$ Banning all tobacco advertising and promotion, particularly that directed at young people, is one of the objectives of the World Health Organization (WHO)'s Framework Convention on Tobacco Control (FCTC). A number of countries have enacted comprehensive advertising bans and positive effects have been reported. ${ }^{4-12}$ China has a serious tobacco epidemic, with over 350 million smokers and about 1 million citizens dying from tobacco-related diseases every year. ${ }^{13} 14$ To prevent tens of millions of people dying from this epidemic urgent action is needed, and comprehensive tobacco advertising bans can be an effective intervention if implemented well. ${ }^{15}$

In China, the 1991 Tobacco Products Monopoly Law (Article 19) and the 1994 Advertisement Law (Article 18) ban direct tobacco advertising on movies, radio, television, newspapers and periodicals. The 1995 Tobacco Advertising Management
Regulations (Article 8) also restricts competitions and programmes connected with tobacco companies. However, restrictions are not comprehensive (see table 1). Compared to countries such as Thailand and Australia, which have strong laws, levels of awareness of tobacco promotion in China are higher, which appears to be a function of problems with enforcing compliance and loopholes (gaps) in the existing laws and regulations. ${ }^{16}$ China officially ratified the WHO FCTC in October 2005, promising to ban all tobacco advertising by January $2011{ }^{17}$ To support this effort, evidence is needed to inform policy makers on any shortcomings of existing legislations and how best to put in place effective and comprehensive tobacco advertising restrictions.

There is no perfect way for assessing the reach and impact of tobacco advertising. One convenient method is to use reports from community members. These have been shown to differentiate countries with differing levels of restrictions on promotion, ${ }^{81618}$ and to detect changes in banspecific forms of promotion. ${ }^{8}$ This method does not give accurate estimates of prevalence of promotions, but is sensitive to relativities and thus can be used to assess differences in exposure between areas, and also to explore patterns of exposure over time. Care is needed to ensure comparability of the respondents, as they can vary widely in their capacity to report accurately. We were particularly interested in whether laws restricting tobacco promotions were evenly implemented and/or enforced across China.

In this study we use data from the baseline wave of the International Tobacco Control (ITC) China survey to explore differences in awareness of tobacco advertising and promotion within China. The aims of this paper are: (i) to examine the levels of awareness of tobacco advertising, promotion and sponsorship among adult smokers and non-smokers in six selected cities of China (ie, Beijing, Guangzhou, Shenyang, Shanghai, Changsha and Yinchuan); and (ii) to examine factors associated with awareness of tobacco advertising, promotion and sponsorship. At the time of our survey (2006) the regulations on tobacco advertising, introduced during the early 1990s, were limited to mainly the broadcast and print media (foreign and local), as shown in table 1 . We expected that the levels of reported awareness of such promotional activities, even among those that are covered by the law, would be high in the selected cities, given that local enforcement tends to be generally poor, and the tobaccocontrol bmicom/site/

about/unlocked.xhtml 
Table 1 National level bans on advertising, promotion and sponsorship in China

\begin{tabular}{|c|c|}
\hline Areas & Banned \\
\hline National television and radio & Yes \\
\hline International television and radio & Yes \\
\hline Local magazines/newspapers & Yes \\
\hline International magazines/newspapers & Yes \\
\hline Billboards/outdoor advertising & No \\
\hline Point of sale & No \\
\hline The internet & No \\
\hline Free distribution & No \\
\hline Promotional discounts & No \\
\hline $\begin{array}{l}\text { Non-tobacco products with tobacco } \\
\text { brand names }\end{array}$ & No \\
\hline $\begin{array}{l}\text { Non-tobacco brand used for } \\
\text { tobacco product* }\end{array}$ & No \\
\hline $\begin{array}{l}\text { Appearance of tobacco products } \\
\text { in television and/or films }\end{array}$ & No \\
\hline Sponsored events & No \\
\hline Enforcement $†$ & $3 / 10$ \\
\hline
\end{tabular}

unrelenting efforts made by tobacco companies to circumvent the laws and regulations. It was unclear, however, whether there would be differences between cities, but any differences found would likely reflect variations in local tobacco control efforts and/ or the presence of large tobacco companies and their marketing activities. For example, among the six cities selected for this study, Changsha, Shenyang and Shanghai have a comparatively greater presence of the tobacco industry. These three cities have large tobacco companies (or their branch factories) that were listed in the 'Top 500 Chinese Companies'. ${ }^{19}$ In Changsha, Baisha Tobacco Group produced over 75 billion cigarettes in 2005, among which about 60 billion cigarettes were produced locally. ${ }^{20}$ Similarly Shenyang's Hongta Liaoning Tobacco Co. Ltd had a local production of 24 billion cigarettes in 2006; and Shanghai Tobacco (Group) Corporation produced 74 billion cigarettes in the same year, of which about 30 billion cigarettes were locally produced. ${ }^{21} 22$ There is no cigarette factory in Yinchuan. In Beijing, the Beijing Cigarette Factory is a branch factory of the Shanghai Tobacco Group, with a comparatively smaller local production capacity ( $<15$ billion cigarettes). Compared to Changsha and Shanghai, Guangzhou also has a smaller local cigarette production. ${ }^{20}$ The large tobacco companies, particularly those in Changsha and Shanghai, have been aggressive in their marketing activities and have used different methods to do so. For example, the Baisha Group has aggressively promoted its corporate image and tobacco products through setting up a website (http://www.baisha.com, see figure 1) and sponsoring athletics/sports teams and cultural activities. ${ }^{20}$

Differences also exist between the six selected cities regarding tobacco control efforts, partly attributable to disparity in economic development and partly to the policy environment. Beijing is among the first cities in China to restrict smoking in public places by introducing the Regulations on Beijing's Nonsmoking Public Places in 1995, although some problems still exist regarding its implementation. ${ }^{23}$ Local regulations/policies on restricting smoking in public places have been enacted in other cities as well, but the enforcement is varied and generally poor, even at venues such as hospitals and schools. ${ }^{24}$ Education and awareness campaigns, such as the 'World No Tobacco Day' and 'Quit and Win', have been conducted in most of the selected cities.

\section{METHODS}

\section{Sampling design and procedures}

The ITC China Survey is a prospective face-to-face cohort survey of adult smokers and non-smokers conducted between April and August 2006 in six cities (800 adult smokers and 200 non-smokers in each city: Beijing, Guangzhou, Shenyang, Shanghai, Changsha and Yinchuan). These cities were selected based on geographical representations and levels of economic development. Within each city there was a random sample selected using a stratified multistage design, with inclusion probabilities proportional to size at the first few stages in each stratum. In each of the 6 cities, 10 Jie Dao (street districts) were randomly selected at the first stage, with probability of selection proportional to the population size of the Jie Dao. Within each selected Jie Dao, two Ju Wei Hui (residential blocks) were selected, again using probability proportional to the population size of the Ju Wei Hui. Within each selected Ju Wei Hui, a complete list of addresses of the dwelling units (households) was first compiled, and then a sample of 300 households was drawn from the list by simple random sampling without replacement. During the enumeration process, information on age, gender and smoking status for all adults living in these 300 households was collected. The enumerated 300 households were then randomly ordered, and adult smokers and non-smokers were then approached following the randomised order until 40 adult smokers and 10 non-smokers were surveyed. Because of low smoking prevalence among women (about $4 \%$ of women aged over 15 years), ${ }^{25}$ one male smoker and one female smoker from every selected household were surveyed whenever possible to increase the sample size for women. At most one non-smoker was interviewed per household. Where there was more than one person in a sampling category to choose from in a household, the next birthday method was used to select the individual to be interviewed.

The enumerators and survey interviewers were organised and trained by staff from local Centers for Disease Control and Prevention (CDCs) in each city. The average time to complete a survey was about $30 \mathrm{~min}$ for smokers and $10 \mathrm{~min}$ for nonsmokers, excluding time to obtain consent. Interviewers followed a strict protocol in their interview session with each respondent. Up to four visits to a household were made in order to interview the target person(s). The wave 1 response rates in the six selected cities were as follows: $61 \%$ in Shanghai; $50 \%$ in Beijing, Guangzhou, Shenyang and Changsha; and 39\% in Yinchuan. $^{26}$

In this paper, a smoker refers to a respondent who had smoked more than 100 cigarettes in his/her lifetime and smoked at least weekly at recruitment. A total of 4763 adult smokers and 1259 non-smokers in the 6 selected cities completed the wave 1 survey. Additional information about the ITC China Survey methodology and sampling is provided by Wu et $\mathrm{al}^{26}$ and available at http://www.itcproject.org.

\section{Relevant measures}

In addition to demographic and smoking-related information, relevant questions measuring respondents' awareness of tobacco advertising and promotional activities were included in the survey. The smokers and non-smokers were asked of the overall salience of pro-smoking cues (unprompted recall): 'In the last 6 months, how often have you noticed things that are designed to encourage smoking or which make you think about 


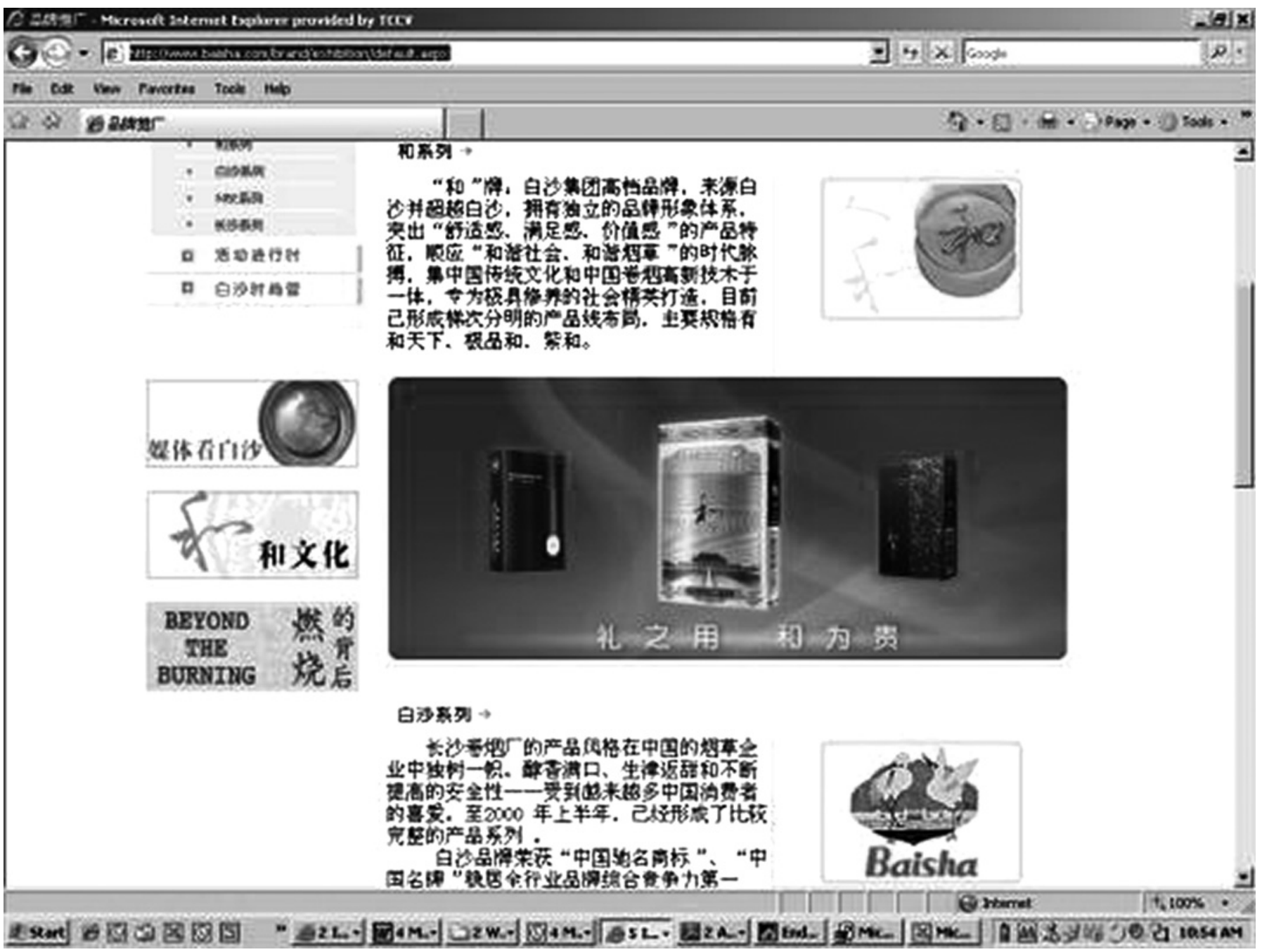

Figure 1 A tobacco advertisement from the website of the 'Baisha Group', promoting the 'He' ('Harmonious') brand of the cigarette company (at the top and in the middle of the web page), as well as its logo ('Baisha' with white cranes at bottom) (source: http://www.baisha.com/brand/exhibition/ default.aspx).

smoking?' (with response options 'never, once in a while, often, very often and don't know'). The smokers (but not the nonsmokers) were then prompted to recall if they had noticed/seen tobacco advertisements in a range of specific locations or media: television, radio, posters, billboards, newspapers or magazines, cinemas, in stores, around street vendors, over the internet, the workplace, public transportation vehicles or stations, cafeterias and in discos lounges or other entertainment venues. There were also questions about smokers' awareness of sports and arts event sponsorships, and of a range of promotional activities, such as free samples of cigarettes and free gifts or special discount offers on other products when buying cigarettes. In addition, smokers were asked to indicate whether they agree or disagree with the following statements regarding tobacco companies and their advertising and promotion: 'Tobacco companies do good things for the Chinese society' and 'Tobacco companies should be allowed to advertise and promote cigarettes as they please' (with response options 'strongly disagree', 'disagree', 'neither disagree nor agree', 'agree', 'strongly agree' and 'cannot say').

\section{Data analyses}

The analyses were conducted on weighted data using SPSS V.14.0 for Windows (SPSS, Chicago, Illinois, USA). Differences between groups were assessed using the Pearson $\chi^{2}$ test and logistic regression models (for categorical variables) and Krus$\mathrm{kal}-$ Wallis test for count variables. An $\alpha$ level of $\mathrm{p}<0.05$ was used for all statistical tests. To facilitate comparisons across cities, several composite variables were computed. For the awareness of tobacco advertising, 2 composite measures were computed for each city and then compared: (i) 'Number of venues noticed tobacco adverts': the sum of all 'yes' responses (total score ranges from 0-13), and (ii) 'noticed tobacco adverts in any of the 13 venues', which scored as 1 for those who noticed advertising in any of the venues and 0 otherwise. Similarly, the following composite variable was created for tobacco sponsorship: 'noticed any type of tobacco sponsorship' (coded 1 for noticing either sports or arts event sponsorship and 0 otherwise). For the composite variable of tobacco promotion 'noticed any form of promotion', code 1 means a respondent reported noticing any of the following five types of promotion: free samples of cigarettes, special price offers, gifts/discounts, branded clothing or competition; otherwise coded as 0 . In addition, two overall indices of awareness across all three forms of tobacco marketing were computed. These were 'total noticing advertising, sponsorship and promotion in any channel' and 'overall number of channels'. 


\section{RESULTS}

\section{Demographic and smoking-related characteristics}

Table 2 presents the demographic and smoking-related characteristics of the respondents. Over $95 \%$ of respondents were of Han ethnicity. The smokers were overwhelmingly men, whereas $54.2 \%$ of the non-smoker sample were women. The majority of respondents were married, aged $40+$, had received some secondary education and had an income of 1000 to 3000 yuan per month (US\$145 to \$440). The vast majority of smokers (93.8\%) smoked only factory-made cigarettes, and about $5 \%$ of smokers reported that they smoked factory-made cigarettes and roll your own cigarettes. Of the 4763 smokers, $16.3 \%$ were heavy smokers, smoking 21 or more cigarettes per day.

\section{Awareness of tobacco advertising and promotional activities and correlated factors}

Without prompting, overall more smokers (40.3\%) than nonsmokers $(25.3 \%)$ reported noticing items that were designed to encourage smoking at least once in a while in the previous 6 months (table 3). Guangzhou had the lowest rates of noticing.

The remainder of the results are restricted to reports of smokers. Table 4 presents prompted recall of noticing tobacco advertisements, sponsorship and promotion among smokers in the six cities. Table 5 presents data on significant differences

Table 2 Demographic and smoking-related characteristics of respondents

\begin{tabular}{|c|c|c|c|c|}
\hline & \multicolumn{2}{|c|}{$\begin{array}{l}\text { Smokers } \\
(\mathrm{n}=4763)\end{array}$} & \multicolumn{2}{|c|}{$\begin{array}{l}\text { Non-smokers } \\
(\mathrm{n}=1259)\end{array}$} \\
\hline & $\bar{n}$ & $\%$ & $\bar{n}$ & $\%$ \\
\hline \multicolumn{5}{|l|}{ Gender } \\
\hline Male & 4566 & 95.9 & 576 & 45.8 \\
\hline Female & 197 & 4.1 & 683 & 54.2 \\
\hline \multicolumn{5}{|l|}{ Ethnicity } \\
\hline Han & 4536 & 95.2 & 1198 & 95.1 \\
\hline Hui & 152 & 3.2 & 40 & 3.2 \\
\hline Man & 57 & 1.2 & 12 & 0.9 \\
\hline Others & 18 & 0.4 & 9 & 0.8 \\
\hline \multicolumn{5}{|l|}{ Age } \\
\hline $18-24$ & 91 & 1.9 & 46 & 3.7 \\
\hline $25-39$ & 859 & 18.0 & 233 & 18.5 \\
\hline $40-54$ & 2268 & 47.6 & 493 & 39.2 \\
\hline $55+$ & 1544 & 32.4 & 487 & 38.7 \\
\hline \multicolumn{5}{|l|}{ Education* } \\
\hline Low & 652 & 13.7 & 138 & 11.0 \\
\hline Medium & 3153 & 66.3 & 735 & 58.4 \\
\hline High & 950 & 20.0 & 386 & 30.6 \\
\hline \multicolumn{5}{|l|}{ Income† } \\
\hline Low & 921 & 20.8 & 223 & 19.4 \\
\hline Medium & 2156 & 48.8 & 592 & 51.6 \\
\hline High & 1345 & 30.4 & 333 & 29.0 \\
\hline \multicolumn{5}{|l|}{ Marital status } \\
\hline Currently married/live with a partner & 4211 & 88.6 & 1112 & 88.8 \\
\hline Currently single & 541 & 11.4 & 140 & 11.2 \\
\hline \multicolumn{5}{|l|}{ Cigarettes per day } \\
\hline $0-10$ & 1658 & 35.0 & - & - \\
\hline $11-20$ & 23.8 & 48.7 & - & - \\
\hline $21+$ & 773 & 16.3 & - & - \\
\hline \multicolumn{5}{|l|}{ Type of cigarettes smoked } \\
\hline Factory-made only & 4459 & 93.8 & - & - \\
\hline Roll your own only & 53 & 1.1 & - & - \\
\hline Both & 241 & 5.1 & - & - \\
\hline
\end{tabular}

*Education: low, no schooling/elementary; medium, secondary; high, tertiary.

tIncome: low, $<1000$ yuan per month; medium, 1000-2999 yuan; high, $\geq 3000$ yuan.
Table 3 Unprompted recall (yes*) of noticing things that encourage smoking among the respondents in the six cities, by smoking status

\begin{tabular}{|c|c|c|c|c|c|c|}
\hline & \multicolumn{2}{|c|}{$\begin{array}{l}\text { Smokers } \\
n=4753\end{array}$} & \multicolumn{2}{|c|}{$\begin{array}{l}\text { Non-smokers } \\
\mathrm{n}=1257\end{array}$} & \multicolumn{2}{|c|}{$\begin{array}{l}\text { Total } \\
\text { respondents } \\
\mathrm{n}=6010\end{array}$} \\
\hline & $\mathrm{n}$ & $\%$ & $n$ & $\%$ & $\mathrm{n}$ & $\%$ \\
\hline Beijing & 327 & 41.2 & 45 & 20.6 & 372 & 36.8 \\
\hline Shenyang & 377 & 47.8 & 73 & 37.4 & 450 & 45.7 \\
\hline Shanghai & 307 & 39.0 & 83 & 40.7 & 390 & 39.2 \\
\hline Changsha & 338 & 42.2 & 44 & 21.8 & 382 & 38.0 \\
\hline Guangzhou & 191 & 24.0 & 23 & 10.3 & 214 & 21.0 \\
\hline Yinchuan & 377 & 47.8 & 49 & 22.9 & 426 & 42.3 \\
\hline Total & 1917 & 40.3 & 317 & 25.3 & 2234 & 37.2 \\
\hline
\end{tabular}

*This includes those who answered 'once in a while' and 'often'; $p<0.001$ ( $\chi^{2}$ test).

between cities for key variables when controlling for characteristics of the smokers. Overall across the six cities, a considerable proportion of smokers reported noticing tobacco advertisements in a range of locations/channels in the last 6 months, with highest exposure levels on television (34.5\%), billboards (33.4\%) and at points of sale $(29.2 \%$ in stores where smokers buy tobacco and $20.3 \%$ around street vendors).

We used the composite measures 'noticed tobacco advertisement in any venue above' and 'number of venues noticed tobacco ad' (table 4) to compare reported levels of noticing tobacco advertising across the six cities. The overall levels of noticing advertisements in any of the venues and the mean number of venues noticed advertisement were highest in Changsha, followed closely by Shenyang, but were relatively low among the smokers in Beijing and Yinchuan.

As for awareness of tobacco sponsorship, about a quarter of smokers reported noticing sport events that were sponsored by or connected with cigarettes brands or tobacco companies, and about $8 \%$ reported noticing arts event sponsorship. Compared to smokers in the other five cities, smokers in Changsha were more likely to report noticing sports and/or arts event sponsorships, with about $45 \%$ of smokers there having reported noticing such sponsorship (120\% more likely to do so compared to Beijing), and it was lowest in Guangzhou and Yinchuan (43\% and 48\% less likely to do so, respectively, compared to Beijing).

Overall, for the five types of tobacco promotional activities listed in table 4, 38.5\% reported noticing any type of them in the last 6 months. Higher proportions of smokers in Yinchuan (49.4\%; $93 \%$ more likely to do so compared to Beijing) and Guangzhou (42.2\%; $66 \%$ more likely to do so compared to Beijing) reported noticing any form of promotion.

Total noticing of all forms of tobacco marketing activities (advertising, sponsorship and promotion) in any channel, as listed in table 4, was $75.6 \%$ among the smokers in the 6 cities, with an average of $3.4(\mathrm{SE}=0.05)$ channels noticed. Smokers in Changsha were the most likely to report noticing in any channel, with those from Beijing least likely.

As can be seen from table 5, compared to smokers in Beijing, smokers in Changsha, Shenyang and Shanghai were more likely to notice advertisements and also for Changsha, sponsorships. Smokers in Guangzhou and Yinchuan and Shanghai were less likely to notice sponsorships. By contrast, smokers in Guangzhou and Yinchuan in particular were more likely to report noticing promotions (particularly price promotions).

As can be seen in table 5, younger smokers were more likely to report noticing all forms of tobacco marketing; male smokers tended to report noticing all elements more often, although this was only significant for sponsorships. The better educated and 
Table 4 Prompted recall of tobacco advertising and promotional activities among smokers $(n=4763)$, by city

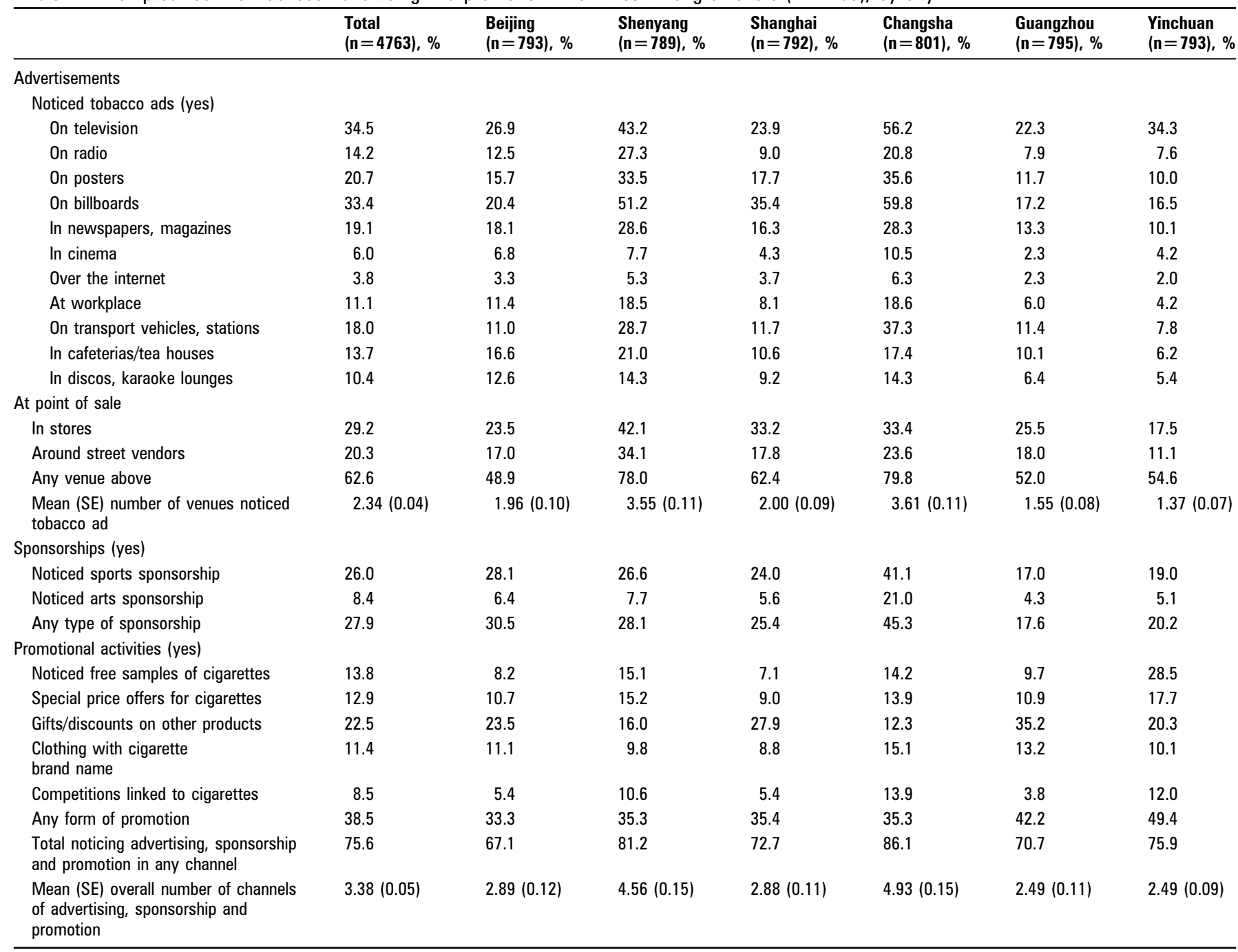

Group differences for all the individual variables of interest are significant at $p<0.01$ level based on Pearson $\chi^{2}$ test.

in particular the more affluent were also more likely to report all forms. Marital status had little effect for advertising awareness but single persons were more likely to notice sponsorships and promotions. By contrast, reported cigarette consumption was unrelated to noticing tobacco marketing activities.

\section{Seeing tobacco use in the entertainment media}

When asked about smoking images in the entertainment media, almost four-fifths of smokers said that they had seen people smoking in the entertainment media at least once in a while in the last 6 months (table 6 ). The highest proportions were reported by smokers in Yinchuan (84.1\%) and Changsha (82\%).

\section{Smokers' attitudes towards tobacco companies' advertising and promotional activities}

About half of the smokers thought that 'tobacco companies do good things for the Chinese society' but only about $17.6 \%$ agreed that tobacco companies should be allowed to advertise and promote cigarettes as they please. Smokers in Shenyang, Beijing and Changsha were the most likely to hold positive attitudes towards the tobacco industry and also to support their advertising and promotional activities (table 6 and figure 2). Both measures (attitudes towards and support for tobacco companies' advertising) were associated with higher levels of reporting noticing of tobacco advertisements (both $p$ values $<0.001)$. Support for advertising restrictions was positively associated with the frequency of noticing tobacco use in the entertainment media $(p<0.001)$. However, there was no linear relationship between believing tobacco companies do good things and frequency of noticing tobacco use in the entertainment media.

\section{DISCUSSION}

A complementary paper to this, which compared reports on awareness of tobacco marketing activities in China to levels in other countries, found that the overall reported awareness was significantly higher among Chinese smokers than their counterparts in Thailand and Australia. ${ }^{16}$ Our data here show that the awareness of tobacco advertising and promotional activities was not homogeneous across the six Chinese cities, suggesting variations in tobacco companies' activities and tobacco control effort in different cities, and by inference in the provinces to which they belong. It is notable that even in the most restrictive cities, levels were typically higher than those reported in countries with comprehensive laws. ${ }^{16}$

We cannot be sure whether the base levels of reporting reflect a common failure to enforce laws or some genuine limitations 
Table 5 Sociodemographic and behavioural correlates of smokers' noticing tobacco advertising and promotional activities

\begin{tabular}{|c|c|c|c|c|c|}
\hline Correlates & $\begin{array}{l}\text { Advertisements } \\
\text { overall (n=4368), } \\
\text { adjusted OR }(95 \% \mathrm{Cl})\end{array}$ & $\begin{array}{l}\text { Advertisements on } \\
\text { billboards ( }=4379) \text {, } \\
\text { adjusted OR }(95 \% \mathrm{Cl})\end{array}$ & $\begin{array}{l}\text { Sponsorships }(n=4379) \text {, } \\
\text { adjusted OR }(95 \% \mathrm{CI})\end{array}$ & $\begin{array}{l}\text { Promotion }(\mathrm{n}=4374) \text {, } \\
\text { adjusted OR }(95 \% \mathrm{Cl})\end{array}$ & $\begin{array}{l}\text { Total noticing advertising, } \\
\text { sponsorship and promotion } \\
\text { ( } \mathrm{n}=4363 \text { ), adjusted } \mathrm{OR}(95 \% \mathrm{CI})\end{array}$ \\
\hline \multicolumn{6}{|l|}{ City } \\
\hline Shenyang & $4.31(3.40 \text { to } 5.45)^{* * *}$ & $4.36(3.43 \text { to } 5.54)^{* * *}$ & 1.01 (0.79 to 1.28$)$ & $1.26(1.00 \text { to } 1.58)^{*}$ & $2.37(1.85 \text { to } 3.05)^{* * *}$ \\
\hline Shanghai & $1.72(1.39 \text { to } 2.13)^{* * *}$ & $2.05(1.62 \text { to } 2.59)^{* * *}$ & $0.76(0.60 \text { to } 0.97)^{*}$ & 1.11 (0.89 to 1.38 ) & 1.25 (0.99 to 1.56$)$ \\
\hline Changsha & $4.67(3.65 \text { to } 5.96)^{* * *}$ & $6.00(4.71 \text { to } 7.66)^{* * *}$ & $2.20(1.74 \text { to } 2.78)^{* * *}$ & 1.09 (0.86 to 1.37$)$ & $3.45(2.62 \text { to } 4.54)^{* * *}$ \\
\hline \multicolumn{6}{|l|}{ Sex } \\
\hline Male & 1.16 (0.83 to 1.62$)$ & $1.53(1.05 \text { to } 2.22)^{*}$ & $1.58(1.05 \text { to } 2.40)^{*}$ & 1.38 (0.96 to 1.97$)$ & 1.31 (0.93 to 1.85$)$ \\
\hline Female & Reference & Reference & Reference & Reference & Reference \\
\hline \multicolumn{6}{|l|}{ Age } \\
\hline $18-24$ & Reference & Reference & Reference & Reference & Reference \\
\hline $25-39$ & $0.69(0.31$ to 1.52$)$ & $0.61(0.34$ to 1.11$)$ & $1.65(0.95$ to 2.86$)$ & 0.99 (0.58 to 1.69$)$ & $0.86(0.35$ to 2.13$)$ \\
\hline Medium & $1.25(1.02 \text { to } 1.55)^{*}$ & $1.26(0.99$ to 1.60$)$ & $1.66(1.26 \text { to } 2.17)^{* * *}$ & $1.12(0.90$ to 1.40$)$ & 1.24 (1.00 to 1.55$)$ \\
\hline High & $1.35(1.04 \text { to } 1.75)^{*}$ & $1.31(0.98$ to 1.75$)$ & $2.38(1.74 \text { to } 3.24)^{* * *}$ & $1.05(0.81$ to 1.37$)$ & $1.31(0.99$ to 1.73$)$ \\
\hline \multicolumn{6}{|l|}{ Income } \\
\hline Low & Reference & Reference & Reference & Reference & Reference \\
\hline Medium & $1.50(1.26 \text { to } 1.79)^{* * *}$ & $1.20(0.99$ to 1.44$)$ & $1.37(1.13 \text { to } 1.67)^{* *}$ & $1.32(1.10 \text { to } 1.57)^{* *}$ & $1.61(1.33 \text { to } 1.95)^{* * *}$ \\
\hline High & $1.70(1.38 \text { to } 2.10)^{* * *}$ & $1.40(1.12 \text { to } 1.74)^{* *}$ & $1.53(1.22 \text { to } 1.93)^{* * *}$ & $1.76(1.44 \text { to } 2.16)^{* * *}$ & $1.82(1.45 \text { to } 2.28)^{* * *}$ \\
\hline \multicolumn{6}{|l|}{ Marital status } \\
\hline Currently married & Reference & Reference & Reference & Reference & Reference \\
\hline Currently single & $1.14(0.90$ to 1.44$)$ & $1.00(0.79$ to 1.26$)$ & $1.36(1.07 \text { to } 1.72)^{*}$ & $1.34(1.08 \text { to } 1.68)^{* *}$ & $1.14(0.88$ to 1.47$)$ \\
\hline \multicolumn{6}{|l|}{ Cigarettes per day } \\
\hline 10 or less & Reference & Reference & Reference & Reference & Reference \\
\hline $11-20$ & $0.93(0.81$ to 1.08$)$ & $0.91(0.78$ to 1.06$)$ & $1.02(0.87$ to 1.20$)$ & $1.08(0.93$ to 1.24$)$ & $1.00(0.85$ to 1.17$)$ \\
\hline
\end{tabular}

ORs are adjusted for all other variables in the model.

${ }^{*}$ Significant at $\mathrm{p}<0.05 ;{ }^{* *} \mathrm{p}<0.01 ;{ }^{* * *} \mathrm{p}<0.001$.

common to the national laws, or the imposition of local laws. The pattern of reporting we found generally reflects the legal situation, except for the high reported prevalence on television. This may be partly because television is such an important source of information and thus may be the default answer for noticing things when the source is not clearly remembered. It could also reflect misremembering depictions of smoking as advertisements or misinterpreting tobacco-sponsored sports events on television as tobacco advertising. To confirm which of these would require content analysis that future studies should consider. Nevertheless, these explanations are made more plausible by the finding that reporting seeing advertising on television was more strongly associated with reporting seeing smoking in the entertainment venue (than for other sources of advertising).

Apart from television, billboards and posters are the main reported sources of advertisements, clearly reflecting the channels that the tobacco companies have taken advantage of because they are not strictly regulated by the government, consistent with experiences from other jurisdictions. ${ }^{27}$ This clearly calls for more comprehensive laws to ban public displays of advertisements and minimise the opportunities for tobacco companies to shift their promotional expenditures to allowable mediums or channels. Point of sale remains an important source and, unless strongly regulated, could become even more important when other sources are more effectively eliminated. ${ }^{18} 28$ Our data suggest that sporting sponsorships are more prominent than arts sponsorships overall. This is in line with findings from Canada that sports sponsorship was more prominent, relative to the arts, which is consistent with sponsorship spending generally. $^{29}$

The differences in reported awareness between cities is likely largely due to differences in the application of the laws,

Table 6 Awareness of smoking images in entertainment media and attitudes towards the tobacco industry among smokers ( $\mathrm{n}=4763$ ), by city

\begin{tabular}{|c|c|c|c|c|c|c|c|}
\hline & $\begin{array}{l}\text { Total } \\
(\mathrm{n}=4763), \%\end{array}$ & $\begin{array}{l}\text { Beijing } \\
(n=793), \%\end{array}$ & $\begin{array}{l}\text { Shenyang } \\
(n=789), \%\end{array}$ & $\begin{array}{l}\text { Shanghai } \\
(n=792), \%\end{array}$ & $\begin{array}{l}\text { Changsha } \\
(n=801), \%\end{array}$ & $\begin{array}{l}\text { Guangzhou } \\
(n=795), \%\end{array}$ & $\begin{array}{l}\text { Yinchuan } \\
(n=793), \%\end{array}$ \\
\hline \multicolumn{8}{|c|}{ See people smoking in the entertainment media } \\
\hline Once in a while & 27.9 & 27.9 & 23.1 & 26.0 & 33.9 & 34.7 & 21.7 \\
\hline Often & 51.5 & 53.1 & 53.2 & 50.6 & 48.1 & 41.5 & 62.4 \\
\hline $\begin{array}{l}\text { Tobacco companies do good } \\
\text { things for the Chinese society } \\
\text { (agree+strongly agree) }\end{array}$ & 50.3 & 58.1 & 55.1 & 52.1 & 46.1 & 38.6 & 51.6 \\
\hline
\end{tabular}




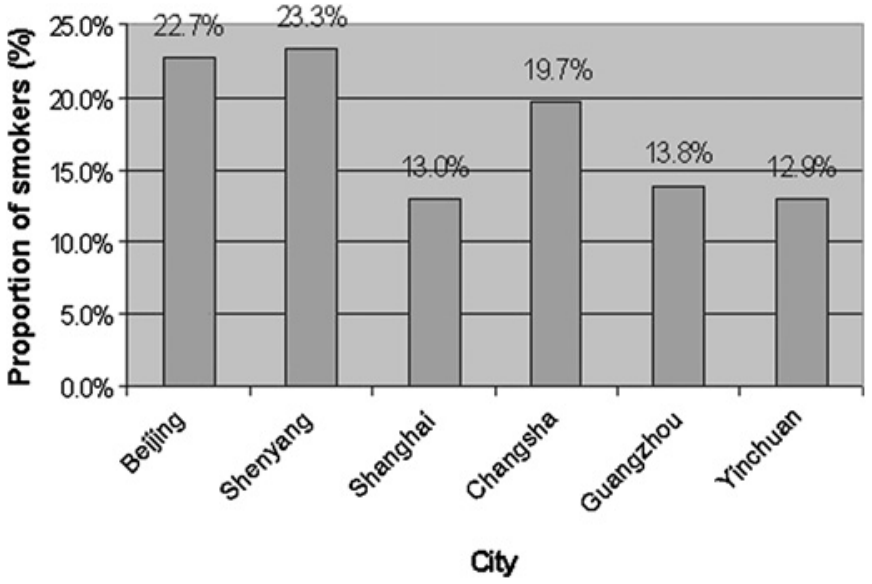

Figure 2 Proportion of smokers agreeing to allow tobacco companies to advertise and promote cigarettes as they please.

suggesting in some cities that the implementation of the laws has not been done well. The pattern of results is also generally consistent with at least some of the variability in reported noticing being due to strategic activity of the tobacco industry. The two cities with the greatest industry presence (Changsha and Shenyang) had the highest levels of noticing tobacco advertising and sponsorships. Cities with low levels of reported advertising (Yinchuan and Guangzhou), and thus presumably more rigorous enforcement of laws, had higher awareness of point of sale tobacco promotion activities (eg, free gifts or special discount offers). The way this occurs may differ by the economic status of the area, thus Yinchuan, a relatively poor city, has more direct price discounting, while Guangzhou, a richer one, reported more value added gifts. From our survey, we cannot say whether these activities are directed by the tobacco manufacturers or are strategies employed by retailers, although especially in the case of add ons, a central role for the manufacturers seems likely.

One striking finding is the smokers' positive attitudes towards the tobacco companies and their promotional activities. Of note is the relatively high positive view of the tobacco industry among Beijing smokers, particularly given its comparatively low levels of reported awareness of tobacco advertising, sponsorship and promotion. The positive view of the tobacco industry, at least some of it, might be grounded in the fact that in China the tobacco industry is mainly owned and administered by the government where there is reasonable expectation that government agencies would operate in the interests of the people. In the case of Beijing, we suspect that it might be due to the indebtedness to the tobacco companies in Beijing that have been a major contributor to local economy and provide employment for many including the smokers in our study. Positive attitudes to the tobacco industry might also be due to exposure to industry communications, particularly those designed to promote the social responsibility of the companies. For example, Changsha's Baisha Tobacco Group has sponsored a number of sport games and athletics; its website (http://www.baisha.com) has tried to convey such a message that the company cares for the public interests; that it is a major tax contributor in Hunan province; and that it is contributing to the development of a harmonious society. ${ }^{20}$ The support for advertising may indicate a lack of public understanding in China of the role of tobacco advertising and promotion in tobacco use initiation and maintenance.

It is worth noting that younger people in this study were more likely to report noticing advertising and promotional

\section{What this paper adds}

This paper demonstrates the diversity of implementation of a central set of laws to restrict tobacco promotion. It clearly demonstrates the need to work with implementation agencies (in this case provincial and perhaps even lower levels of government) if national laws are to be properly implemented and enforced.

- We acknowledge that the diversity in implementation may be facilitated by gaps in the existing laws, thus allowing wriggle room for provinces less motivated to implement them fully.

activities than the older smokers. There could be various reasons for this. Younger people could be more ready to report noticing, with or without prompting, something found in the USA. ${ }^{30}$ They may be more exposed to some channels (eg, the billboards, via greater mobility and the internet). We do not know to what extent, if at all, any real effects are due to deliberate industry targeting

This study has some limitations. As noted earlier, respondents' reports of events or things they may have noticed are never precise and are often affected by internal factors such as memory bias and external factors such as amount of competing material in the environment. Thus, caution should be exercised when making inferences about differences in pattern or level of recall across environments where similarity in contextual factors cannot be assumed. The results reflect the situation in the six selected Chinese cities. It may be that in other cities and the vast rural areas of China, smokers' awareness of tobacco advertising and promotion may be different. Further research on more broadly based samples will be required to fill in these gaps. The relative contribution of foreign or transnational tobacco companies towards reported levels of tobacco advertising and promotional activities in China is unclear but is likely to increase given China's large market, an attractive prize for many transnational tobacco companies. ${ }^{31} 32$ Finally, the undersampling of smokers aged 18-29 could have some effects as well. Many in this age group were absent at school/university or in jobs like the military. They may respond differently to the ones still at home, so the weighting procedures might not control for their absence.

Despite the above limitations, the results demonstrate that levels of smokers' awareness of tobacco advertising, promotion and sponsorship varies by area, demonstrating the importance of regional level policy implementation, even in a country where many external people might expect uniformity of policy implementation. The findings highlight the need for coordinated effort from all lower levels of government (from provincial to city) to implement national laws consistently.

Acknowledgements The authors would like to acknowledge the Chinese Center for Disease Control and Prevention and local CDC representatives in each city for their role in data collection. We are grateful to the anonymous reviewers who provided useful suggestions on earlier drafts of this paper.

Funding The ITC China project was supported by grants from the US National Cancer Institute (R01 CA125116 and the Roswell Park Transdisciplinary Tobacco Use Research Center (P50 CA111236)), Canadian Institutes of Health Research (79551), Chinese Center for Disease Control and Prevention and the Ontario Institute for Cancer Research. The funding sources had no role in the study design, in collection, analysis and interpretation of data, in the writing of the report, or in the decision to submit the paper for publication.

Competing interests None. 
Ethics approval Ethics approval was obtained from the Office of Research Ethics at the University of Waterloo (Waterloo, Canada) and the internal review boards at: Roswell Park Cancer Institute (Buffalo, USA), the Cancer Council Victoria (Melbourne, Australia) and the Chinese Center for Disease Control and Prevention (Beijing, China).

Contributors YY, XW and QL supervised the collection and management of the ITC China data and provided input on description of Chinese context, especially policies regarding tobacco advertising restrictions and the tobacco industry's activities. LL, HY, $\mathrm{RB}, \mathrm{CW}$ and $\mathrm{KF}$ provided insights on relevant international literature, sampling/measurement description, data analysis and presentation. All eight authors made significant contributions to different versions of the manuscript. YY, LL and XW conducted the data analysis and coordinated input from the other authors, who are based in different countries. $\mathrm{RB}, \mathrm{HY}$ and $\mathrm{LL}$ contributed considerably in editing the English version and in enhancing the Discussion.

Patient consent Obtained.

Provenance and peer review Not commissioned; externally peer reviewed.

\section{REFERENCES}

1. Sargent JD, Dalton $\mathrm{M}$, Beach $\mathrm{M}$. Effect of cigarette promotion on smoking uptake among adolescents. Prev Med 2000;30:320-7.

2. Lovato C, Linn G, Stead LF, et al. Impact of tobacco advertising and promotion on increasing adolescent smoking behaviours. Cochrane Database Syst Rev 2003;(4): CD003439

3. US Department of Health and Human Services. Reducing the Health Consequences of Smoking: 25 Years of Progress: A Report of the Surgeon General. DHHS Publication No. (CDC) 89-8911. Atlanta, GA: Centers for Disease Control and Prevention, Office on Smoking and Health, 1989.

4. Saffer H. Tobacco advertising and promotion. In: Jha P, Chaploupka F, eds. Tobacco control in developing countries. Oxford: Oxford University Press, Inc.; 2000:215-36.

5. Canadian Cancer Society. Controlling the tobacco epidemic: selected evidence in support of banning all tobacco advertising and promotion, and requiring larger picturebased health warnings on tobacco packages. Ottawa: Canadian Cancer Society, International Union Against Cancer, 2001.

6. Keeler T, Hu T, Ong M, et al. US National Tobacco Settlement: the effects of advertising and price changes on cigarette consumption. Appl Econ 2004:36:1623-9.

7. National Cancer Institute. Influence of tobacco marketing on smoking behavior. In: Davis $\mathrm{R}$, Gilpin $\mathrm{E}$, Loken B, et al, eds. The role of the media in promoting and reducing tobacco use. Tobacco control monograph No.19. Bethesda, MD: US Department of Health and Human Services, National Institutes of Health, National Cancer Institute, 2008:211-91.

8. Harris F, MacKintosh AM, Anderson S, et al. Effects of the 2003 advertising/ promotion ban in the United Kingdom on awareness of tobacco marketing: findings from the International Tobacco Control (ITC) Four Country Survey. Tob Control 2006;15(Suppl 3):iii26-33.

9. Chitanondh $\mathbf{H}$. Thailand country report on tobacco advertising and promotion bans. Tobacco control, WHO tobacco control papers. San Francisco: University of California, 2003.

10. Saffer $\mathbf{H}$, Chaloupka F. The effect of tobacco advertising bans on tobacco consumption. J Health Econ 2000;19:1117-37.

11. Chapman S, Wakefield M. Tobacco control advocacy in Australia: reflections on 30 years of progress. Health Educ Behav 2001:28:274-89.
12. Jha $\mathbf{P}$, Chaloupka FJ. Curbing the epidemic: governments and the economics of tobacco control. Washington, DC: The World Bank, 1999.

13. Yang GH, Ma JM, Liu N, et al. Smoking and passive smoking in Chinese, 2002 (Published in Chinese). Zhonghua Liu Xing Bing Xue Za Zhi 2005:26:77-83.

14. Sung H-Y, Wang L, Jin S, et al. Econominc burden of smoking in China, 2000. Tob Control 2006:15(Suppl 1):i5-11.

15. World Health Organization. WHO report on the global tobacco epidemic, 2008: the MPOWER package. Geneva: World Health Organization, 2008. p36-8.

16. Li L, Yong HH, Borland $\mathrm{R}$, et al. Reported awareness of tobacco advertising and promotion in China compared to Thailand, Australia and the USA. Tob Control 2009;18:222-7. doi: 10.1136/tc.2008.027037 [published Online First: 29 March 2009].

17. Xinhua News Agency. China to ban all tobacco advertising by 2011. 2007. http:// www2.chinadaily.com.cn/china/2007-08/28/content_6063029.htm laccessed 2 Apr 2009).

18. Yong H-H, Borland R, Hammond D, et al. Levels and correlates of awareness of tobacco promotional activities among adult smokers in Malaysia and Thailand: findings from the International Tobacco Control Southeast Asia (ITC-SEA) survey. Tob Control 2008:17:46-52.

19. Liu S. The top 500 Chinese companies of 2007 were in their orders - Hunan's Zhongyan Industry (Baisha) Group was ranked the 135th. Hunan Tobacco (in Chinese). 2007:5.

20. Baisha Group. Our history: major events. Changsha, 2008. http://www.baisha.com/ groupconcept/develop/default.aspx (accessed 16 Sep 2008).

21. China Tobacco Information Network. [Introduction to] Shanghai Tobacco (Group) Corporation Shanghai Cigarette Factory. 2008 http://www.echinatobacco.com/ 101542/101575/101599/8636.html (accessed 16 Sep 2008)

22. State Tobacco Monopony Administration of China. China Tobacco Yearbook 2006 (in Chinese). Beijing: China Economy Publishing House, 2008:207-691.

23. Chen YH, Wang $Y$, Zhang $X$, et al. Study on the attitudes of implementation of the smoking bans in public places among community residents in Beijing. Chinese Journal of Health Education 2008;24:746-8

24. Yan J, Xiao S, Ouyang D, et al. Smoking behavior, knowledge, attitudes and practice among health care providers in Changsha city, China. Nicotine Tob Res 2008; 10:737-44.

25. Yang GH. Report on the 1996 Nationwide Survey of Smoking Prevalence. Beijing: China Science and Technology Press, 1997.

26. Wu C, Thompson ME, Fong GT, et al. Methods of the International Tobacco Contro (ITC) China Survey. Tob Control. Published Online First: 2009 Jul 30. doi:10.1136/ tc. 2009.029900

27. Bayer R, Gostin L, Javitt G, et al. Tobacco advertising in the United States: A proposal for a constitutionally acceptable form of regulation. JAMA 2002;287:2990-5.

28. Vateesatokit $\mathbf{P}$, Hughes $B$, Ritthiphakdee $B$. Thailand: winning battles, but the war's far from over. Tob Control 2000:9:122-7.

29. Dewhirst T. Smoke and ashes: Tobacco sponsorship of sports and regulatory issues in Canada. Chapter 17 (pp. 327-52) In: Kahle LR, Riley C, eds. Sports Marketing and the Psychology of Marketing Communication. Mahwah, NJ: Lawrence Erlbaum Associates, Inc. 2004

30. Farrelly M, Healton C, Davis $\mathrm{K}$, et al. Getting to the truth: evaluating national tobacco countermarketing campaigns. Am J Public Health 2002;92:901-7.

31. Lee K, Gilmore A, Collins J. Breaking and re-entering: British American Tobacco in China 1979-2000. Tob Control 2004:13(Suppl 2):ii88-95.

32. O'Sullivan B, Chapman S. Eyes on the prize: transnational tobacco companies in China 1976-1997. Tob Control 2000:9:292-302. 